JURNAL Midwifery Update (MU)

http://jurnalmu.poltekkes-mataram.ac.id/index.php/jurnalmu

e-ISSN: 2684-8511 (Online)

\title{
STUDY LITERATUR PENGARUH SENAM PEROUDIK (PEREGANGAN OTOT PERUT DAN KOMPRES DINGIN) TERHADAP PENURUNAN NYERI HAID PADA REMAJA PUTRI
}

Endah Rahayu ${ }^{1}$, Lina Sundayani ${ }^{2}$

1,2 Jurusan Kebidanan Poltekkes Kemenkes Mataram

\begin{abstract}
Abstrak
Latar Belakang : Dismenore atau nyeri haid merupakan keluhan ginekologi yang umum dialami perempuan. Nyeri haid ini merupakan suatu gejala dan bukan suatu penyakit. Hampir semua wanita mengalami rasa tidak enak pada perut bagian bawah saat menstruasi. Uterus atau rahim terdiri atas otot yang juga berkontraksi dan relaksasi.

Tujuan : Untuk mengetahui pengaruh Senam peregangan otot perut dan kompres dingin Terhadap Penurunan Nyeri Haid Pada Remaja Putri.

Metode : Menggunakan studi literatur berdasarkan refrensi yang relevan dari judul terkait kemudian di analisis secara mendalam untuk menghasilkan sebuah kajian komperhensif mengenai objek penelitian. Peneliti melakukan pencarian journal melalui dengan menggunakan kata kunci dan berbasis journal, melalui Gogle Scholar,Garba Rujukan Digital (GARUDA Ristekdikti) dan Google Search. Literatur yang di gunakan adalah yang di publikasikan dari tahun 2015 sampai dengan 2020.

Hasil : Berdasarkan hasil 20 jurnal yang telah direview dan didapatkan hasil dari 8 jurnal yaitu sebagian besar karakteristik Responden usia menarche yaitu 12-18 tahun dan rata-rata nyeri yang di rasakan dari hasil review ke 8 jurnal sebagian besar intensitas nyeri berada pada nyeri sedang. Peregangan otot perut dan kompres dingin terdapat pengaruh dalam penurunan nyeri haid pada remaja.

Kesimpulan: Dari hasil literatur review ini dapat ditarik kesimpulan bahwa untuk usia haid pertama kali berada pada rentang usia 12-18 dan nyeri yang dirasakan pada saat menstruasi nyeri sedang serta peregangan otot perut dan kompres dingin mampu menurunkan nyeri haid.
\end{abstract}

\section{Kata Kunci : Senam peregangan otot perut, kompres dingin, Nyeri Haid}

\section{LITERATURE STUDY OF THE EFFECT OF PERIODIC EXERCISE (STRETCHING OF THE ABDOMINAL MUSCLES AND COLD COMPRESSES) ON THE REDUCTION OF MENSTRUAL PAIN IN ADOLESCENT GIRLS}

\begin{abstract}
Background : Dysmenorrhea or painful menstruation is a common gynecological complaint experienced by women. Menstrual pain is a symptom and not a disease. Almost all women experience discomfort in the lower abdomen during menstruation. The uterus or uterus is made up of muscles which also contract and relax

Research Objectives: To determine the effect of stretching the abdominal muscles and cold compresses on the reduction of menstrual pain in young women.

Research Methods : Using literature studies based on relevant references from related titles then analyzed in depth to produce a comprehensive study of the object of research. Researchers searched journals using keywords and journal-based, through Google Scholar, Digital
\end{abstract}


Reference Garba (GARUDA Ristekdikti) and Google Search. The literature used is the one published from 2015 to 2020.

Results: Based on the results of 20 journals that have been reviewed and obtained results from 8 journals, most of the characteristics of the respondents are aged menarche, namely 12-18 years and the average pain felt from the results of the review of the 8 journals, most of the pain intensity is in moderate pain. Stretching the abdominal muscles and cold compresses have an effect in reducing menstrual pain in adolescents.

Conclusion: From the results of this review literature, it can be concluded that the age of first menstruation is in the age range 12-18 and the pain felt during menstruation is moderate pain and stretching of the abdominal muscles and cold compresses can reduce menstrual pain.

\section{Keywords: Abdominal muscle stretching, cold compresses, menstrual pain}

\section{Pendahuluan}

Masa remaja merupakan periode terjadinya pertumbuhan dan perkembangan yang pesat baik secara fisik, psikologis, maupun intelektual.Remaja adalah penduduk dalam rentang usia 10-18 tahun dan menurut Badan Kependudukan dan Keluarga Berencana (BKKBN) rentang usia remaja adalah 10-24 tahun dan belum menikah (Kemenkes RI, 2014.).

Menurut beberapa laporan Internasional prevelensi dismenorea sangat tinggi dan setidaknya $50 \%$ remaja putri mengalami desminorea sepanjang tahun reproduktif. Hasil studi terbaru menunjukan bahwa hampir 10\% remaja yang desmenorea mengalami absen sekolah dan absen kerja 1-3 hari perbulan atau kemampuan remaja dalam melakukan tugas sehari-hari akibat nyeri hebat (Umi Dkk, 2010).

Angka kejadian dismenorea didunia sangat besar. Rata-rata 50\% perempuan disetiap Negara mengalami dismennore. Di Amerika Serikat diperkirakan 45-90\% perempuan mengalami dismenore yaitu 12\% nyeri berat,37\% Nyeri sedang,49\% nyeri ringan. (Fransiska \& Novita, 2018)

Banyak hal dilakukan untuk mengurangi dismenore yang mereka rasakan saat datang bulan, mulai dari minum hangat sebanyak 62\%, mengkonsumsi paracetamol 37\%, dan digunakan untuk tidur sebanyak 45\% (Ngu,2013)Dalam penelitian yang dilakukan di negara Pakistan sebanyak $327 \%$ remaja yang mengalami dismenore mengkonsumsi analgetik untuk mengurangi rasa sakitnya, dan $73 \%$ remaja tidak mengkonsumsi analgetik karena mereka beranggapan bahwa dismenore merupakan hal biasa terjadi pada remaja saat berada pada siklus datang bulan.

Hasil penelitian menyatakan bahwa exercise efektif dalam menurunkan dismenorea primer (Arifiani Ayu, 2016). Hasil penelitian menyatakan bahwa senam dismenorea pada remaja (Arifiani Ayu, 2016), Kadar endorphin dalam tubuh yang meningkatkan dapat mengurangi rasa nyeri pada saat kontraksi. Abdominal Stretching exercise merupakan suatu latihan peregangan otot terutama pada bagian perut yang dilakukan selama 10 menit. Latihanlatihan ini dirancang untuk meningkatkan kekuatan otot, daya tahan dan fleksibel otot. Sehingga diharapkan dapat menurunkan dismenore pada wanita.

Menurut penelitian oleh (Fauziah Nur Mia, 2015), exercise yang efektif menurunkan skala Dismenore adalah abdominal stretching exercise untuk meningkatkan kekuatan otot perut kelenturan perut dan daya tahan tubuh pada keadaan tertentu, serta relaksasi pernapasan untuk pengendoran, pelepasan ketegangan dan meningkatkan ventilasi paru sehingga oksigen darah dapat menurunkan skala Dismenore. Abdominal stretching exercise merupakan salah 
satu teknik relaksasi yang dapat digunakan untuk mengurangi nyeri. Hal ini disebabkan saat melakukan olahraga atau senam tubuh akan menghasilkan endorphin. Endorphin dihasilkan di otak dan susunan syaraf tulang belakang yang berfungsi sebagai obat penenang alami yang diproduksi otak sehingga menimbulkan rasa nyaman. Dengan adanya dukungan teori pengamatan dan study lateratur yang dilakukan pada remaja yang mengalami nyeri haid (dismenorea) terapi yang di berikan peregangan otot perut dan kompres dingin peneliti tertarik untuk menggali lebih dalam mengenai pengaruh senam Peregangan otot perut dan kompres dingin terhdap penurunan nyeri haid pada remaja putri.

\section{Metode Penelitian}

Menggunakan studi literatur berdasarkan refrensi yang relevan dari judul terkait kemudian di analisis secara mendalam untuk menghasilkan sebuah kajian komperhensif mengenai objek penelitian. Peneliti melakukan pencarian journal melalui dengan menggunakan kata kunci dan berbasis journal, melalui Gogle Scholar,Garba Rujukan Digital (GARUDA Ristekdikti) dan Google Search. Literatur yang di gunakan adalah yang di publikasikan dari tahun 2015 sampai dengan 2020.

Desain penelitian menggunakan dimana design penelitian dalam literature riview ini menggunakan desing quasi ekspriment dan random control lokasi yang digunakan untuk literatur riview ini bertepatan di Pondok Pesantren Al-Aziziyah. Adapun waktu yang digunakan selama 1 bulan dari 1 Mei sampai 30 Mei.

\section{Hasil Penelitian Dan Pembahasan}

Berdasarkan hasil jurnal review dari 20 jurnal terdapat 7 jurnal yang memiliki pengaruh yang sama terhadap penurunan nyeri haid pada remaja, dan memiliki metode desain Quasi Eksperimental, dengan rancangan Control Group Design pretest and posttest dan menggunakan satu kelompok pretest.Tempat penelitian dari artikel dilakukan di tempat yang berbeda.

\section{Karakteristik yang meliputi Usia Menarche, rasa nyeri saat menstruasi}

Penelitian yang dilakukan oleh (Arifiani Ayu, 2016), penelitian ini bertujuan untuk mengetahui efektivitas latihan peregangan perut dalam mengurangi dismenore. Hasil penelitian ini menunjukan bahwa usia menarce responden dalam penelitian ini termasuk dalam kategori remaja madya yang berada pada rentang usia remaja 15- 18 tahun (remaja madya). Remaja akan mengalami perubahan pada organ reproduksinya yang ditandai dengan menstruasi pertama kali yang disebut dengan menarche. Berdasarkan data responden dalam penelitian ini, didapatkan rata-rata usia responden pertama kali menstruasi pada usia 12 dan 14 tahun. Berdasarkan penelitian (Arifiani Ayu, 2016) menyatakan bahwa menarche terjadi pada usia rata-rata 12 tahun 18 . Untuk usia haid pertama (menarche) di dapatkan bahwa responden yang paling banyak mengalami menarche yaitu berada pada usia 12 tahun 17.

Berdasarkan penelitian Yuliana Peratama 2017, tujuan penelitian ini untuk mengetahui pengaruh latihan abdominal stretching terhadap tingkat nyeri haid pada remaja putri. Hasil

penelitian karakteristik usia responden pada kelompok intervensi latihan abdominal stretching 
dan kelompok kontrol rata-rata usia responden yaitu 16 tahun dengan usia minimum 15 tahun dan maksimum 17 tahun (50\%),

Berdasarkan Penelitian (Windastiwi \& Pujiastuti, 2017), tujuan dari penelitian ini untuk mengetahui pengaruh latihan peregangan perut dengan intensitas nyeri dismenore dari hasil penelitian Krakteristik intensitas nyeri Penelitian ini menunjukkan bahwa dari 48 responden, sebagian besar responden (75\%) mengalami dismenorea sedang, terdapat 8 responden yang mengalami dismenorea berat dan 4 responden mengalami dismenorea ringan. Hasil penelitian sebelum abdominal stretching exercise sebagian besar responden mengalami dismenorea sedang (75\%). Hasil penelitian sebelum abdominal stretching exercise sebagian besar responden mengalami dismenorea sedang (75\%). Penelitian ini membuktikan bahwa dengan melakukan abdominal stretching exercise dapat menurunkan intensitas nyeri dismenorea. Berdasarkan nilai rata-rata nyeri dismenorea yang dialami sebelum melakukan abdominal stretching exercise adalah 5,27 dan sesudah melakukan abdominal stretching exercise adalah 4,62. Tingkat nyeri dismenorea setelah latihan abdominal stretching exercise lebih rendah apabila dibandingkan dengan sebelum latihan abdominal stretching. intensitas Nyeri Dismenorea Sebelum Perlakuan.

Berdasarkan penelitian (Salbiah alfarizah, 2018), tujuan penelitian ini adalah untuk mengetahui efektifitas latihan abdominal stretching terhadap tingkat nyeri saat menstruasi pada remaja putri hasil penelitian. Hasil penelitian krakteristik rentang usia 15-25 tahun dengan persentase $87 \%$ pada jumlah responden 100 orang. Penelitian lainnya oleh (Afrizal Salbiah, 2018), menunjukkan bahwa rata-rata usia responden yang mengalami dismenore adalah 1735 tahun. Dismenore primer umumnya dimulai pada 1-3 tahun setelah haid pertama (menarche). Kasus ini bertambah berat 78 beberapa tahun hingga usia 23-27 tahun. Hasil penelitian skala nyeri sebelum perlakuan (pre) yang paling banyak ditemui pada skala nyeri 46 atau berada pada kategori nyeri sedang yaitu sebanyak 37 responden dengan persentase $66,1 \%$. Skala nyeri setelah perlakuan (post) yang paling banyak ditemui pada skala nyeri 1-3 atau berada pada kategori nyeri ringan yaitu sebanyak 50 responden dengan persentase $89,3 \%$. Berdasarkan uji statistik t test berpasangan didapatkan bahwa ada perbedaan yang signifikan antara skala nyeri sebelum dan setelah melakukan latihan abdominal stretching dalam mengurangi skala nyeri dismenore. bahwa usia responden yang paling banyak adalah berusia 19 tahun dengan jumlah 28 responden dengan persentase 50\%. Sedangkan usia responden yang paling sedikit berusia 21 tahun dengan jumlah 2 responden dengan persentase 3,6\%.

Berdasarkan Penelitian (Amalia et al., 2020), tujuan penelitian ini untuk mengetahui perbedaan kompres air hangat dan kompres air dingin terhadap penurunan intensitas nyeri pada remaja putri dengan dismenore berdasarkan Hasil penelitian menunjukkan bahwa Krakteristik intensitas nyeri sesudah diberikan kompres air dingin rata-rata 3,65, intensitas nyeri terendah 3 dan intensitas nyeri tertinggi 5. Hal ini menunjukkan adanya penurunan skala nyeri dismenore sesudah diberikan kompres air dingin. Hasil penelitian menunjukkan bahwa terdapat perbedaan intensitas nyeri sebelum dan sesudah diberi kompres air hangat pada remaja putri dengan dismenore ( $\mathrm{p}$ value $0.000<0.05)$. Terdapat perbedaan intensitas nyeri sebelum dan sesudah diberi kompres air dingin pada remaja putri dengan dismenore ( $\mathrm{p}$ value $0.000<$ 0.05). Kompres air hangat lebih efektif dalam menurunkan intensitas nyeri daripada kompres air dingin pada remaja putri dengan dismenore. 
Berdasarkan 20 jurnal yang telah di review dari beberapa jurnal yang menyatakan bahwa hasil analis yang membahas tentang karakteristik usia menarche yaitu sebagian besar usia menarche 12-18 tahun dan rata-rata nyeri yang di rasakan dari hasil review beberapa jurnal intensitas nyeri berada pada nyeri ringan dan nyeri sedang yang menandakan dari skala nyeri yaitu dengan penggolongan $1-3=$ nyeri ringan, $4-6=$ nyeri sedang

Hal ini sesuai dengan teori yang mengatakan bahwa menstruasi dimulai antara usia 12-15 tahun, tergantung pada berbagai faktor seperti. kesehatan wanita, status nutrisi dan pola hidup sehat (Amilia, 2018). Usia 17 tahun sampai 20 tahun merupakan usia remaja lanjut. Sesuai dengan teori (Amilia, 2018), mengatakan bahwa pada masa pubertas remaja putri, ditandai dengan kematangan organ-organ seks primer dan ciri-ciri sekunder. Ciri dari perkembangan seks primer yaitu adanya perkembangan rahim, vagina dan ovarium (indung telur) secara cepat.

Remaja yang mengalami nyeri haid (dismenore) disebabkan karena adanya kejang otot uterus yang dapat dimulai pada 24 jam sebelum terjadinya perdarahan haid dan dapat bertahan selama 24-36 jam, umumnya berlangsung 24 jam pertama saat terjadi perdarahan haid (Peratama, Yuliana, 2017). Dismenore merupakan kondisi normal khususnya pada wanita yang sedang mengalami menstruasi, namun nyeri menstruasi dapat muncul berlebihan karena dipengaruhi oleh beberapa factor seperti fisik, psikis seperti stres dan hormon prostaglandin yang tinggi,hormone prostaglandin yang disekresi berlebihan akan berdifusi ke dalam jaringan endometrial yang akan meningkatkan amplitudo dan frekuensi kontraksi uterus, sehingga mengakibatkan iskemia uterus dan hipoksia pada jaringan uterus, dan disintegrasi endometrium, perdarahan serta kram abdomen bawah yang merangsang nyeri saat menstruasi (Peratama,Yuliana, 2017).

Hal yang menyebabkan nyeri tak tertahankan pada responden yaitu adanya produksi hormon adrenalin, estrogen, progesteron dan prostaglandin yang berelebihan. Estrogen dapat menyebabkan peningkatan kontraksi uterus secara berelebihan sedangkan progesterone bersifat menghambat kontraksi. Peningkatan kontraksi berlebihan dapat menebabkan rasa nyeri. Selain itu hormon adrenalin yang meningkat juga menyebabkan otot tubuh tegang termasuk otot rahim yang menjadikan nyeri saat menstruasi (Peratama,Yuliana, 2017)

Hasil penelitian ini menunjukkan skala intensitas nyeri dismenore responden bervariasi karena nyeri yang dirasakan individu satu dengan yang lainnya tidak sama. Sesuai yang disampaikan (Amalia et al., 2020) bahwa perbedaan nyeri ini dipengaruhi oleh beberapa factor seperti usia, jenis kelamin, kultur/budaya, dukungan keluarga/sosial, dan koping. Kondisi tubuh seseorang yang tidak akan sama satu dengan yang lainnya yang disebabkan oleh perbedaan kadar endorphin. Endorphin berfungsi mengatur berbagai fungsi fisiologi transmisi nyeri, emosi, kontrol nafsu makan dan sekresi hormon. Perbedaan kadar endorphin yang tinggi akan sedikit merasakan nyeri dan kadar endorphin yang sedikit akan merasakan nyeri yang berlebih (Amalia et al., 2020).

\section{Menganalisa Pengaruh Peregangan Otot perut terhadap penurunan nyeri haid pada remaja}

Penelitian (Arifiani Ayu, 2016)penelitian ini bertujuan untuk mengetahui efektivitas latihan peregangan perut dalam mengurangi dismenore berdasarkah hasil peneliian Setelah 
diberikan latihan peregangan perut (abdominal stretching exercise) ada penurunan skala dismenore pada kelompok intervensi sedangankan pada kelompok kontrol tidak diberikan intervensi apapun pada saat mengalami dismenore dan hasilnya tidak ditemukan penurunan skala dismenore pada kelompok kontrol. Berdasarkan hasil penelitian dan teori yang telah diuraikan diatas peneliti menyatakan latihan peregangan perut (abdominal stretching exercise) efektif dalam mengurangi dismenore pada remaja putri.

Penelitian (Peratama, Yuliana, 2017), tujuan penelitian ini adalah Tujuan penelitian ini untuk mengetahui pengaruh latihan abdominal stretching terhadap tingkat nyeri haid pada remaja putri berdasarkan hasil penelitian Berdasarkan penelitian ini tingkat nyeri haid pada tabel 4.2 diketahui bahwa tingkat nyeri haid setelah dilakukan latihan abdominal stretching rata-rata nyeri 1,46 dan rata-rata nyeri sebelum dilakukan latihan abdominal stretching adalah 4,58. Dengan rata-rata nyeri pada kelompok kontrol adalah 4,48. Jadi pada penelitian ini dapat disimpulkan bahwa ada pengaruh latihan abdominal stretching terhadap penurunan tingkat nyeri haid pada remaja dengan dismenore.

Penelitian (Windastiwi \& Pujiastuti, 2017), tujuan dari penelitian ini untuk mengetahui pengaruh latihan peregangan perut dengan intensitas nyeri dismenore berdasarkan hasil penelitian Penelitian ini membuktikan bahwa dengan melakukan abdominal stretching exercise dapat menurunkan intensitas nyeri dismenorea. Berdasarkan nilai rata-rata nyeri dismenorea yang dialami sebelum melakukan abdominal stretching exercise adalah 5,27 dan sesudah melakukan abdominal stretching exercise adalah 4,62. Tingkat nyeri dismenorea setelah latihan abdominal stretching exercise lebih rendah apabila dibandingkan dengan sebelum latihan abdominal stretching.

penelitian (Nike, 2017) Bertujuan mengetahui gambaran pengaruh pemberian abdominal stretching exercise terhadap penurunan nyeri desminore Berdasarkan hasil penelitian menunjukkan gambaran perbedaan remaja yang mengalami dismenore diperoleh rata-rata nilai yang dilakukan sebesar 2.87 (nyeri ringan) dengan dengan nilai median 3.00, skala nilai minimum 2.00 dan skala nilai maksimum 4.00 Kemudian rata-rata yang tidak dilakukan sebesar 4.87 (nyeri sedang). nilai median 5.00, skala minimum 3.00 dan skala maksimum 6.00. Hasil uji Wilcoxon didapatkan nilai significancy $0.001(\mathrm{p}<0.05)$, demikian dapat disimpulkan bahwa ada perbedaan skala nyeri dismenore dilakukan dan tidak dilakukan abdominal stretching exercise pada siswi di SMP N 30 Semarang.

Penelitian (Afrizal Salbiah, 2018), tujuan penelitian ini adalah untuk mengetahui efektifitas latihan abdominal stretching terhadap tingkat nyeri saat menstruasi pada remaja putri hasil penelitian berdasarkan hasil penelitian Berdasarkan hasil penelitian ini peneliti dapat menyimpulkan bahwa latihan abdominal stretching merupakan intervensi yang mudah, murah dan menggunakan proses fisiologis tubuh. Terapi ini digunakan untuk menurunkan kontraksi uterus, mengurangi kram pada abdomen bagian bawah, dan memperlancar peredaran darah, sehingga pada akhirnya dapat menurunkan intensitas nyeri pada remaja dengan dismenore.

Berdasarkan hasil 5 literatur review sebagian besar menyatakan salah satu olahraga untuk menurnkan intensitas nyeri haid adalah dengan melakukan abdominal stretching exercise. Abdominal stretching exercise yang dilakukan pada saat dismenore untuk meningkatkan kekuatan otot, daya tahan, dan fleksibilitas otot, mengurangi rasa nyeri otot dan ketegangan otot sehingga dapat menurunkan intensitas nyeri haid (dismenore). Tujuan dari 
latihan peregangan otot adalah membantu meningkatkan oksigenasi (proses pertukaran oksigen dan karbohidrat di dalam sel) serta menstimulase aliran drainase getah bening, sehingga dapat menigkatkan kelenturan otot dan dapat memelihara fungsinya dengan baik serta memperbaiki elastisitas dan fleksibilitas jaringan tubuh sehingga mengurangi kram pada otot (Peratama, Yuliana, 2017).

Hal ini sesuai dengan (Salbiah alfarizah, 2018)yang menyatakan bahwa salah satu olahraga yang dapat dilakukan untuk menurunkan intensitas nyeri haid (dismenorea) adalah dengan melakukan abdominal stretching. Abdominal stretching, yang dilakukan untuk meningkatkan kekuatan otot, daya tahan dan fleksibilitas otot dapat meningkatkan kebugaran, mengoptimalkan daya tangkap, meningkatkan mental dan relaksasi fisik, meningkatkan perkembangan kesadaran tubuh, mengurangi ketegangan otot (kram), mengurangi nyeri otot dan mengurangi rasa sakit pada saat menstruasi.

\section{Pengaruh kompres dingin terhadap penurunan nyeri haid pada remaja putri}

Penelitian (Fransiska \& Novita, 2018) tujuan penelitian ini adalah untuk mengetahui pengaruh kompres dingin terhadap penurunan intensitas nyerti pada wanita dewasa yang mengalami nyeri dismenore, berdasarkan hasil penelitian Berdasarkan Tabel3 didapatkan bahwa nilai $\mathrm{p}$ value $=(0,000)<(0,050)$ yang artinya "pemberian kompres dingin berpengaruh terhadap penurunan intensitas nyeri pada wanita dewasa yang mengalami dismenore di Rayon IKABE Tlogomas". Sedangkan didapatkan nilai $Z=(-3,750)$ yang artinya pemberian kompres dingin mampu menurunkan intensitas nyeri 3,75 kali lebih cepat pada wanita dewasa yang mengalami dismenore. Hasil tabulasi silag membuktikan sebelum diberikan kompres dingin $(70 \%)$ wanita dewasa mengalaminyeri berat terkontrol sedangkan sesudah diberikan kompres dingin terdapat penurunan intensitas nyerisebanyak $(60 \%)$ wanita mengalami nyeri sedang di Rayon IKABE Tlogomas.

Berdasarkan Penelitian (Amalia et al., 2020), tujuan penelitian ini untuk mengetahui perbedaan kompres air hangat dan kompres air dingin terhadap penurunan intensitas nyeri pada remaja putri dengan dismenore. Berdasarkan hasil penelitian ini juga dapat dilihat perbandingan keefektifitasan dari kedua perlakuan terhadap intensitas nyeri pada penderita dismenorea. Uji statistik untuk mengetahui perbandingan tersebut dengan menggunakan uji Mann-Whitney. Berdasarkan hasil uji tersebut diketahui ada perbandingan perubahan rata-rata intensitas nyeri antara kompres hangat dan kompres dingin. Rata-rata selisih perubahan intensitas nyeri pada kelompok kompres air hangat sebesar 2,65 dan kompres air dingin sebesar 1,41, dapat dilihat perubahan rata-rata intensitas nyeri pada kelompok kompres air hangat lebih efektif menurunkan dismenorea.

Berdasarkan beberapa jurnal yang di review kompres dingin berpengaruh terhadap penurunan intensitas nyeri pada wanita dewasa yang mengalami dismenore. Penanganan nyeri dapat dilakukan dengan cara farmakologi dan non farmakologi. Managemen nyeri non farmakologis dapat dilakukan untuk membantu untuk mengurangi nyeri secara tepat dan tidak memerlukan waktu yang lama dan biaya yang mahal. Secara farmakologi dapat diberikan obat penurunan nyeri atau analgesik sedangkan dengan cara non medis dapat dilakukan dengan tehnik relaksasi dan distraksi. Salah satu cara teknik distraksi adalah distraksi visual pengelihatan, distraksi audio/pendengaran sedangkan dengan teknik relaksasi adalah dengan 
mengajarkan cara napas dalam dan pemberian kompres. Kompres dibagi menjadi dua yaitu kompres hangat dan dan kompres dingin (Fransiska \& Novita, 2018)

Kompres dingin bekerja dengan menstimulasi permukaan kulit untuk mengontrol nyeri. Terapi dingin yang diberikan mempengaruhi impuls yang dibawa oleh serabut taktil ABeta untuk lebih mendominasi sehingga akan menutup impuls nyeri akan terhalangi (Fransiska \& Novita, 2018). Kompres dingin dapat diletakan pada daerah yang terasa nyeri biasanya pada bagian pinggang, perut bagian bawah atau lipatan paha ketika ada kontraksi dengan menggunakan buli- buli dingin yang diisi dengan air dingin dengan suhu $15-18^{\circ} \mathrm{C}$ selama 5 10 menit karena suhu air sudah turun dan harus diganti (Fransiska \& Novita, 2018).

Hasil penelitian ini sesuai dengan penelitian yang dilakukan oleh (Amalia et al., 2020), membuktikan terdapat perbedaan rasa nyeri yang dialami responden sebelum dengan sesudah diberikan kompres dingin, hal ini membuktikan bahwa kompres dingin berpengaruh secara signifikan terhadap penurunan nyeri dikarenakan kompres dingin dapat menurunkan aliran darah ke daerah tubuh yang mengalami nyeri. Kompres dingin yang mengurangi intensitas nyeri dikarenakan oleh kadar endorphin seseorang, semakin tinggi kadar endorphin maka semakin ringan rasa nyeri yang dirasakan. Produksi endorphin dapat ditingkatkan melalui stimulasi kulit. Stimulasi kulit salah satunya yaitu dengan tindakan kompres dingin. Mekanisme penurunan nyeri dengan pemberian kompres dingin berdasarkan atas teori endorphin. Endhorpin merupakan zat penghilang rasa nyeri yang diproduksi oleh tubuh. Semakin tinggi kadar endorphin seseorang, semakin ringan rasa nyeri yang dirasakan. Produksi endorphin dapat ditingkatkan melalui stimulasi kulit. Stimulasi kulit meliputi massase, penekanan jari-jari dan pemberian kompres hangat atau dingin.

Hasil penelitian ini sesuai dengan penelitian yang dilakukan oleh (Irawan Deby Faulus, 2018), setelah diberikan kompres dingin mengalami nyeri dismenore ringan, sehingga efektifitas pemberikan tekhnik relaksasi nafas dalam dan kompres dingin mampu menurunkan tingkat nyeri dismenore pada mahasiswi.

Penelitian yang dilakukan oleh Muttaqin (Irawan Deby Faulus, 2018) menunjukkan bahwa pemberian kompres air dingin dapat mengurangi inte

nsitas nyeri dismenore. Sedangkan (Purnamasari) dalam penelitiannya menyimpulkan bahwa pasien fraktur yang diberikan kompres dingin mengalami penurunan nyeri yang signifikan. Hasil penelitian menyatakan bahwa stimulasi kulit dengan teknik kompres dingin lebih efektif dalam menurunkan persepsi nyeri.

\section{Study literature pengaruh senam peregangan otot perut dan kompre dingin terhadap penurunan nyeri haid pada remaja.}

Penelitian (Peratama, Yuliana, 2017), tujuan penelitian ini untuk mengetahui pengaruh latihan abdominal stretching terhadap tingkat nyeri haid pada remaja putri. Berdasarkan hasil penelitian Berdasarkan penelitian ini tingkat nyeri haid pada tabel 4.2 diketahui bahwa tingkat nyeri haid setelah dilakukan latihan abdominal stretching rata-rata nyeri 1,46 dan rata-rata nyeri sebelum dilakukan latihan abdominal stretching adalah 4,58. Dengan rata-rata nyeri pada kelompok kontrol adalah 4,48. Jadi pada penelitian ini dapat disimpulkan bahwa ada pengaruh latihan abdominal stretching terhadap penurunan tingkat nyeri haid pada remaja dengan dismenore. 
Penelitian (Salbiah alfarizah, 2018), tujuan penelitian untuk mengetahui efektifitas latihan abdominal stretching terhadap tingkat nyeri saat menstruasi pada remaja putri berdasarkan hasil penelitian Hasil penelitian tentang perbedaan pengaruh sebelum dan sesudah dilakukan latihan abdominal stretching terhadap tingkat dismenore menunjukkan bahwa rata-rata (mean) intensitas nyeri pada saat sebelum dilakukan latihan abdominal stretching adalah 3,18 dan rata-rata intensitas nyeri setelah dilakukan latihan abdominal stretching adalah 1,96. Berdasarkan uji statistik $t$ testberpasangan didapat nilai $\mathrm{p}$ sebesar 0,0001. Dengan demikian nilai $p$ lebih kecil dari nilai $\alpha(5 \%)$ atau 0,05 sehingga Ha diterima yang berarti ada pengaruh yang signifikan dari latihan abdominal stretching dalam mengurangi skala nyeri dismenore.

Berdasarkan penelitian (Arifiani Ayu, 2016), penelitian ini bertujuan untuk mengetahui efektivitas latihan peregangan perut dalam mengurangi dismenore. Berdasarkanhasil penelitian Dengan demikian berdasarkan hasil penelitian dan teori yang telah diuraikan diatas peneliti menyatakan latihan peregangan perut (abdominal stretching exercise) efektif dalam mengurangi dismenore pada remaja putri di SMA Panca Bhakti Pontianak tahun 2016. Oleh karena itu latihan peregangan perut (abdominal stretching exercise) dapat dijadikan metode untuk mengurangi dismenore pada remaja putri khususnya pada remaja putri di SMA Panca Bhakti Pontianak tahun 2016.

Penelitian (Nike, 2017), mengetahui gambaran pengaruh pemberian abdominal stretching exercise terhadap penurunan nyeri desminore pada remaja di SMP N 30 Semarang. Berdasarkan hasil penelitian menunjukkan bahwa gambaran perbedaan remaja yang mengalami dismenore diperoleh rata-rata nilai yang dilakukan sebesar 2.87 (nyeri ringan) dengan dengan nilai median 3.00, skala nilai minimum 2.00 dan skala nilai maksimum 4.00 Kemudian rata-rata yang tidak dilakukan sebesar 4.87 (nyeri sedang), nilai median 5.00, skala minimum 3.00 dan skala maksimum 6.00. Hasil uji wilcoxon didapatkan nilai significancy $0.001(\mathrm{p}<0.05)$, demikian dapat disimpulkan bahwa ada perbedaan skala nyeri dismenore dilakukan dan tidak dilakukan abdominal stretching exercise pada siswi di SMP N 30 Semarang.

Hasil penelitian (Fransiska \& Novita, 2018) tujuan penelitian ini adalah untuk mengetahui pengaruh kompres dingin terhadap penurunan intensitas nyerti pada wanita dewasa yang mengalami nyeri dismenore di Rayon IKABE Tlogomas. Berdasarkan hasil penelitian tabel 3 didapatkan sebelum pemberian kompres dingin sebanyak $14(70,0 \%)$ responden yang mengalami nyeri berat terkontrol sedangkan sesudah sesudah pemberian kompres sebanyak $9(45,0 \%)$ responden mengalami nyeri sedang. Penelitian ini mengunakan uji Wilconxon signed rank test untuk menentukan pengaruh data yang menggunakan desain quasy eksperimen, sedangkan keapsahaan data dilihat dari tingkat signifikasi p-value kurang dari 0,050. Hasil uji wilconxon signed ranktest membuktikan bahwa p value $=(0,000)<$ $(0,050)$ yang artinya "pemberian kompres dingin berpengaruh terhadap penurunan intensitas nyeri pada wanita dewasa yang mengalami dismenore di Rayon IKABE Tlogomas".

Penelitian (Irawan Deby Faulus, 2018), tujuan penelitian ini adalah untuk membandingkan tekhnik relaksasi nafas dalam dan kompres dingin terhadap penurunan tingkat nyeri dismenore pada mahasiswi di Asrama Sanggau dan Ikatan Keluarga Belu di Landungsari Kota Malang. Berdasarkan hasil penelitian Hasil penelitian menunjukkan bahwa kompres 
dingin dapat digunakan sebagai salah satu alternatif untuk menurunkan tingkat nyeri pada mahasiswi yang mengalami dismenore karena kompres dingin relatif tidak memiliki afek samping. Kegunaan kompres dingin untuk mengurangi perdarahan serta edema yang menimbulkan efek analgetik dengan memperlambat hantaran sehingga implus nyeri mencapai otak lebih sedikit. Mekanisme kompres dingin yaitu membantu proses vasokonstriksi dan penurunan metabolisme, membantu mengontrol perdarahan dan mengurangi nyeri.

Penelitian (Amalia et al., 2020), tujuan penelitian ini untuk mengetahui perbedaan kompres air hangat dan kompres air dingin terhadap penurunan intensitas nyeri pada remaja putri dengan dismenore. Berdasarkan hasil penelitian ini juga dapat dilihat perbandingan keefektifitasan dari kedua perlakuan terhadap intensitas nyeri pada penderita dismenorea. Uji statistik untuk mengetahui perbandingan tersebut dengan menggunakan uji Mann-Whitney. Berdasarkan hasil uji tersebut diketahui ada perbandingan perubahan rata-rata intensitas nyeri antara kompres hangat dan kompres dingin. Rata-rata selisih perubahan intensitas nyeri padakelompok kompres air hangat sebesar 2,65 dan kompres air dingin sebesar 1,41, dapat dilihat perubahan rata-rata intensitas nyeri pada kelompok kompres air hangat lebih efektif menurunkan dismenorea.

\section{Kesimpulan}

Berdasarkan hasil literature review maka dapat ditarik kesimpulan.

1. Hasil studi literatur menunjukkan sebagian besar karakteristik remaja putri terbanyak usia menarche 12-18 tahun dan sebagian besar menyatakan rasa nyeri saat menstruasi yang di rasakan yaitu nyeri sedang.

2. Hasil studi literature menunjukkan bahwa senam peregangan otot ada pengaruh terhadap penurunan nyeri haid pada remaja putri.

3. Hasil studi literature mrnunjukkan bahwa kompres dingin ada pengaruh terhadap penurunan nyeri haid pada remaja putri.

4. Hasil studi literature menunjukkan bahwa senam Peregangan otot perut dan kompres dingin berpengaruh terhadap penurunan nyeri haid pada remaja putri.

\section{Daftar Pustaka}

1. Afrizal Salbiah. (2018). Penurunan Tingkat Nyeri Saat Menstruasi Melalui Latihan Abdominal Stretching. Jurnal Ilmu Keperawatan.

2. Amalia, A. R., Susanti, Y., \& Haryanti, D. (2020). EFektivitas kompres air hangat dan air dingin terhadap penurunan intensitas nyeri pada remaja putri dengan dismenore. Jurnal Kebidanan, 1, 7-15.

3. Amilia, A. (2018). Pengaruh pemberian latihan abdominal stretching terhadap penurunan intensitas nyeri haid (disminore) pada remaja putri stikes madani yogyakarta. Jurnal Kesehatan, 9(2), 12-18. https://doi.org/2088-2246

4. Arifiani Ayu. (2016). Efektifitas latihan Peregangan otot Perut ( Abdominal Stretching Exerices Dalam Mengurangi dismenore pada Remaja Putri.

5. Dkk, Umi. 2010. (2010). Pengaruh Terapi Kompres Hangat Terhadap Nyeri Haid (Dismenorea) Pada Siswi SMK Perbankan Simpang Hari Padang. 2(February), 3744.https://doi.org/http://dx.doi.org/10.22216/jen.v2i1.278 
6. Fauziah Nur Mia. (2015). Pengaruh Latihan Abdominal Stretching terhadap Intensitas Nyeri Haid Dismenore Pada Remaja Putri. Skripsi.

7. Fransiska, S., \& Novita, D. (2018). Pengaruh Kompres Dingin Terhadap Penurunan Intensitas Nyeri Pada Wanita Mengalami Dismenore. Jurnal Keperawatan, 3(1).

8. Irawan Deby Faulus. (2018). Perbandingan Thenik Relaksasi Nafas Dalam dan Kompres Dingin Terhadap Penurunan Tingkat Nyeri Haid (Dismenore)Pada Mahasiswi Diasrama Sanggau dan Ikatan Keluarga Belu. Jurnal Perawat, 3(1).

9. Kemenkes RI, 2014. Kemenkes RI 2014. 1-7.

10.Larasati, T., \& Alatas, F. (2016). Dismenore Primer dan Faktor Risiko Dismenore Primer pada Remaja Primary Dysmenorrhea and Risk Factor of Primary Dysmenorrhea in $\begin{array}{llll}\text { Adolescent. } & \text { Majority, } & \text { 79-84), }\end{array}$ http://juke.kedokteran.unila.ac.id/index.php/majority/article/download/1040/835

11.Nikmah, A. N. (2019). Pengaruh Abdominal Sretching Terhadap Perubahan Nyeri Dismenorea Primer Pada Remaja Putri. Journal of Chemical Information and Modeling, 53(9), 1689-1699. https://doi.org/10.1017/CBO9781107415324.004

12.Peratama,Yuliana, F. (2017). Latihan Abdominal Streching Menunkan Tingkat Nyeri Haid Remaja Putri. Retrieved from https://www.google.com/search?q=Latihan+abdominal+strecing + menurunkan+nyeri + haid + remaja + putri\&oq $=$ Latihan + abdominal + strecing + menurunkan + nyeri + haid + remaja + putri $\&$ aqs $=$ chrome..69i57.38167j0j7\&sourceid $=$ chrome\&ie $=U T F-8$

13.Pudjowati, V. E., \& Widodo, D. W. (2016). Nursing News Volume 3, Nomor 1, 2018. Nursing News, 1, 358-368.

14.Salbiah alfarizah. (2018). Penurunan Tingkat Nyeri Saat Menstruasi Melalui Latihan Abdominal Stretching The Menstruation Pain Level Decline By Abdominal Stretching Exercise memberikan perhatian yang serius terhadap ( latihan fisik ) dapat mengatasi dismenore dan kegiatan atau aktiv. Jurnal Ilmu Keperawatan 2338-6371.

15.Windastiwi, W., \& Pujiastuti, W. (2017). Pengaruh abdominal stretching exercise terhadap intensitas nyeri dismenorea. Jurnal Kebidanan Vol 6 No 12, 6(12), 17-26. 